\title{
Article \\ Electrophoresis-Aided Biomimetic Mineralization System Using Graphene Oxide for Regeneration of Hydroxyapatite on Dentin
}

\author{
Ingrid Patricia Khosalim ${ }^{\dagger}$, Yu Yuan Zhang ${ }^{\dagger}$, Cynthia Kar Yung Yiu (D) and Hai Ming Wong *(D)
}

Citation: Khosalim, I.P.; Zhang, Y.Y.; Yiu, C.K.Y.; Wong, H.M.

Electrophoresis-Aided Biomimetic

Mineralization System Using

Graphene Oxide for Regeneration of

Hydroxyapatite on Dentin. Materials 2022, 15, 199. https://doi.org/

$10.3390 / \mathrm{ma} 15010199$

Academic Editor: Paolo Cappare

Received: 21 October 2021

Accepted: 24 December 2021

Published: 28 December 2021

Publisher's Note: MDPI stays neutral with regard to jurisdictional claims in published maps and institutional affiliations.

Copyright: (C) 2021 by the authors. Licensee MDPI, Basel, Switzerland. This article is an open access article distributed under the terms and conditions of the Creative Commons Attribution (CC BY) license (https:// creativecommons.org/licenses/by/ $4.0 /$ )
Paediatric Dentistry and Orthodontics, Faculty of Dentistry, The University of Hong Kong, Hong Kong SAR China; ingridpk@connect.hku.hk (I.P.K.); zyuyuan@hku.hk (Y.Y.Z.); ckyyiu@hku.hk (C.K.Y.Y.)

* Correspondence: wonghmg@hku.hk; Tel.: +852-28-590-261

+ These authors contributed equally to this work.

Abstract: Graphene oxide (GO) is an emerging luminescent carbon nanomaterial with the ability to foster hydroxyapatite (HA). A specially designed electrophoresis system can be used to accelerate the mineralization process. The aim of this study was to promote HA crystal growth on demineralized dentin using a GO incorporated electrophoresis system. GO was successfully synthesized by carbonization of citric acid and its presence was confirmed by Fourier transform infrared and UV-visible spectrophotometry evaluation. Dentin slices were placed in demineralized solution and divided into control (without the electrophoresis system) and experimental group. Demineralized dentin slices in the experimental group were remineralized using the electrophoresis system for $8 \mathrm{~h} / 1.0 \mathrm{~mA}$, with one subgroup treated without GO and the other with GO. Energy dispersive spectroscopy evaluation showed that the calcium/phosphate ratio of the crystal formed in control and experimental group with addition of GO was close to natural hydroxyapatite. However, scanning electron microscopy evaluation showed that the exposed dentinal tubules were occluded with rod-like crystals, which is similar to native enamel morphology, in the experimental group with addition of GO compared to the flake-like crystal in the control group. Mechanical evaluation revealed that the nanohardness and modulus of remineralized dentin were significantly higher in the experimental group. In conclusion, GO is a promising material to remineralize dentin and the introduction of an electrophoresis system can accelerate its process.

Keywords: graphene oxide; hydroxyapatite; electrophoresis

\section{Introduction}

Tooth structure consists of enamel and dentin-pulp complex. Enamel acts as a barrier that protects dentin-pulp complex from physical, thermal, and chemical stimuli [1]. Dentin is vital tissue consisting of dentinal tubules, extension of odontoblasts, and formation of dentin-pulp complex. It has the capacity to respond to physiologic and pathologic stimuli [2].

Hydroxyapatite (HA) is an inorganic material found in $70 \%$ of dentin, along with other trace elements. HA exhibits bioactive properties because it has natural response of cells and mineralization process [3]. HA-particles have high polarity and the ability to bind to both collagen and HA from dentin. HA-particles occlude dentin tubules by being pressed into the tubule opening. HA-particles that bind to the tubules will be mineralized by calcium and phosphate ions from saliva [4,5].

Biomimetic mineralization is an innovative way to mimic natural process of mineralization. It aims to introduce calcium and phosphate ions on demineralized lesion which results in remineralization [6]. A number of biomimetic mineralization methods have been reported, such as a hydrothermal method [1], application of acidic calcium phosphate paste containing hydrogen peroxide and phosphoric acid [7]. Other methods include the 
use of bioactive glass [8], surfactants [9], nano-HA and proline [10], amelogenin [11,12], gelatin [13], dendrimer [14], ethylenediaminetetraacetic acid (EDTA) [15], polyethylene oxide, polyacrylamide [16], and polydopamine [17]. The use of induced pluripotent stem cells (iPSCSs) has been explored and proposed as an alternative in regeneration of mineralized tooth components or supporting tissue [18]. In vitro study showed that biomimetic mineralization was able to regenerate HA [19]. However, in the aforementioned methods, the rate of remineralization is very slow, limiting the clinical application.

Electrophoresis-aided mineralization system is one of the many biomimetic mineralization methods for regenerating HA [2]. The electrophoresis system transports ions better through gels or solutions compared to only diffusion. Agarose hydrogels can be used to promote the synthesis of HA. [20,21]. The electrophoresis system allows ions to move in a one-dimension direction specifically. Advanced movement of calcium and phosphate ions in the agarose hydrogels was observed after electric current was generated. A novel electrophoresis-aided mineralizing system was created to promote the diffusion of calcium and phosphate ions and to accelerate the speed of mineralization [2]. Numerous in vitro studies have proved the efficacy of the electrophoresis system. A study by Wu et al. successfully remineralized a completely demineralized dentin collagen matrix by using the electrophoresis-aided biomineralization system. Another study by Zhang et al. conducted in vitro and in vivo evaluation in which it was observed that electrophoresis could improve the remineralization process of casein phosphopeptide-amorphous calcium phosphate $(\mathrm{CPP}-\mathrm{ACP})$ and the demineralized enamel surface was completely remineralized after treatment of $5 \mathrm{~h}[20,22,23]$.

Graphene oxide (GO) is an emerging luminescent carbon nanomaterial. It is an atomically thin sheet of graphite and oxygen-containing functional groups are covalently decorated, either on the basal plane or at the edges. GO has favorable characteristics such as biocompatibility, low toxicity, strong mechanical strength, and high elasticity and flexibility [24]. In addition, GO has the ability to foster hydroxyapatite, which is an important component in mineralization process. GO could promote remineralization with express HA growth, forming a coating of homogenous and compacted HA/GO and consisting flake-shaped HA crystals with marked elevated calcium-phosphate ration [7,25-27].

With the ability of GO to foster HA growth and electrophoresis system to accelerate HA formation, the aim of this research was to promote HA crystal growth using GO incorporated electrophoresis system. We hypothesized that HA crystal growth could be promoted by the use of GO incorporated electrophoresis system.

\section{Materials and Methods}

\subsection{Specimen Preparation}

This study was approved by The University of Hong Kong/Hospital Authority Hong Kong West Cluster Institutional Review Board (IRB UW17-009). This study was carried out in accordance with approved guideline for research involving human subjects. Extracted third molars with sound enamel were obtained from participants with patients' written informed consent. Teeth were rinsed with normal saline, cleaned ultrasonically to remove the debris, and fixed in 10\% buffered formalin (Sigma-Aldrich, St. Louis, MO, USA) for at least 3 months. Dentin slices of $2 \mathrm{~mm}$ thickness were prepared perpendicular to the longitudinal axis of the tooth using a low-speed diamond saw (IsoMet Low Speed Saw, Buehler, Lake Bluff, IL, USA). Silicon carbide papers with 600-, 1200-, 2400-, and 3000-grit were used for polishing. The slices were ultrasonically cleaned and stored at $4{ }^{\circ} \mathrm{C}$ in deionized water.

\subsection{Lesion Formation and $\mathrm{pH}$ Cycling}

Two dentin slices were used to study sound dentin. Dentin slices were placed in a demineralization solution $\left(2.2 \mathrm{mM} \mathrm{CaCl}_{2} \cdot 2 \mathrm{H}_{2} \mathrm{O}, 2.2 \mathrm{mM} \mathrm{KH}_{2} \mathrm{PO}_{4}, 50 \mathrm{mM}\right.$ acetate, $\left.\mathrm{pH} 4.4\right)$ for $96 \mathrm{~h}$ at $37^{\circ} \mathrm{C}$ to create lesions of $70-100 \mathrm{~mm}$ deep. After the demineralization process, the dentin slices were rinsed thoroughly with deionized water. Dentin slices were $\mathrm{pH}$ 
cycled at room temperature through a $30 \mathrm{~min}$ immersion in demineralization solution $\left(1.5 \mathrm{mM} \mathrm{CaCl}_{2}, 0.9 \mathrm{mM} \mathrm{KH}_{2} \mathrm{PO}_{4}, 50 \mathrm{mM}\right.$ acetate) at $\mathrm{pH} 5.0$ followed by a $10 \mathrm{~min}$ immersion in remineralization solution (20 $\mathrm{mM} 4-(2$ hydroxyethyl)-1 piperazineethanesulfonic acid (HEPES), $\left.1.5 \mathrm{mM} \mathrm{CaCl}_{2}, 0.9 \mathrm{mM} \mathrm{KH}_{2} \mathrm{PO}_{4}, 150 \mathrm{mM} \mathrm{KCl}\right)$ at $\mathrm{pH}$ 7.0. The $\mathrm{pH}$-cycling procedure was performed six cycles per day for 8 days [28]. All of the solutions were freshly prepared for use in the experiment. Dentin slices were stored in deionized water at $4{ }^{\circ} \mathrm{C}$ overnight. At the end of the cycling period, all specimens were washed with deionized water, and air dried.

\subsection{Synthesis of $G O$}

Pyrolyzing citric acid was used to synthesize GO. First, 1 gr of citric acid (SigmaAldrich, St. Louis, MO, USA) was put into a $5 \mathrm{~mL}$ beaker and heated to $200{ }^{\circ} \mathrm{C}$. After $5 \mathrm{~min}$, the citric acid was liquefied and the color changed from colorless to yellow. After $30 \mathrm{~min}$, the color changed to orange. The heating was kept until it changed into black liquid in $100 \mathrm{~min}$, suggesting the formation of GO. The black liquid was then added to $\mathrm{KH}_{2} \mathrm{PO}_{4}$ solution (Sigma-Aldrich, St. Louis, MO, USA) and by $80 \mathrm{mg} / \mathrm{mL} \mathrm{KOH}$ solution to obtain $1.55 \mathrm{M} \mathrm{KH}_{2} \mathrm{PO}_{4}$ solution $0.8 \mathrm{wt} \% \mathrm{GO}$ with $\mathrm{pH}$ 6.5. [29,30]. The solution was stored at $4{ }^{\circ} \mathrm{C}$ before use.

\subsection{Characterization of $\mathrm{GO}$}

The Fourier transform infrared (FTIR) spectra were obtained on a FTIR spectrophotometer (Thermo Nicolet 360, GMI, Ramsey, NJ, USA) equipped with an attenuated total reflection (ATR) sampling accessory. Spectra were recorded at room temperature, in the wavenumber range of $4000-500 \mathrm{~cm}^{-1}$, with an incident laser power of $1 \mathrm{~mW}$ and a minimum resolution of $4 \mathrm{~cm}^{-1}$. FTIR were used to identify pure substances, mixtures, impurities, and compositions of GO. UV-Vis absorption was characterized by a UV/Vis/NIR spectrophotometer (Lambda 750, PerkinElmer Inc., Akron, OH, USA).

\subsection{Preparation of the Mineralizing Medium in Agarose Hydrogel}

A $\mathrm{CaCl}_{2}$-agarose hydrogel was prepared by mixing $1.0 \mathrm{~g}$ agarose powder (Regular Agarose G-10, BIOWEST, Nuaille, France) into $100 \mathrm{~mL}$ of a $0.13 \mathrm{M} \mathrm{CaCL}_{2}$ solution $\left(\mathrm{CaCl}_{2} \cdot 2 \mathrm{H}_{2} \mathrm{O}\right.$, Sigma-Aldrich, St. Louis, $\mathrm{MO}$, USA). A $\mathrm{KH}_{2} \mathrm{PO}_{4}$-agarose hydrogel was prepared by mixing $1.0 \mathrm{~g}$ agarose powder into $100 \mathrm{~mL}$ of a $1.55 \mathrm{M} \mathrm{KH}_{2} \mathrm{PO}_{4}$ solution (SigmaAldrich, St. Louis, MO, USA) containing 500 ppm fluoride (Sigma-Aldrich, St. Louis, MO, USA). A GO-agarose hydrogel was prepared by mixing $1.0 \mathrm{~g}$ agarose powder into $100 \mathrm{~mL}$ of $1.55 \mathrm{M} \mathrm{KH}_{2} \mathrm{PO}_{4}$ solution containing $0.8 \mathrm{wt} \% \mathrm{GO}$ (Sigma-Aldrich, St. Louis, MO, USA) and 500 ppm fluoride (Sigma-Aldrich, St. Louis, MO, USA). The $\mathrm{pH}$ value of the solutions was adjusted to 6.5 using $0.1 \mathrm{M} \mathrm{KOH}$ and $0.1 \mathrm{M} \mathrm{HCl}$. The mixtures were enhanced for $30 \mathrm{~min}$ and then heated to $100{ }^{\circ} \mathrm{C}$ until agarose was completely dissolved.

\subsection{Regeneration of Hydroxyapatite in Agarose Hydrogel Aided by Electrophoresis}

Six dentin slices were used to study the structure and mechanical properties of completely demineralized dentin. Eighteen dentin slices were allocated into experimental $(n=12)$ and control group $(n=6)$. Dentin slices in experimental group were equally allocated into group $\mathrm{A}$ (without the addition of $\mathrm{GO}$ ) and group $\mathrm{B}$ (GO with $0.8 \%$ ). In group $\mathrm{A}$ and control group, dentin slices were placed between the $\mathrm{CaCl}_{2}$ agarose hydrogel and the $\mathrm{KH}_{2} \mathrm{PO}_{4}$ agarose hydrogel [23]. In the group $\mathrm{B}$, dentin slices were placed between the $\mathrm{CaCl}_{2}$ agarose hydrogel and the GO-phosphate agarose hydrogel which were put into the two sides of the tube. The tubes were then connected to the plastic cells. Electrodes were set into the bottom of the cells, which were filled with $0.9 \% \mathrm{NaCl}$ solution to enhance the electrical conductivity. Dentin slices in group A and B were treated with electrophoresis system. The electric current was maintained constant at $1.0 \mathrm{~mA}$, during electrophoresis [2]. The gels and $\mathrm{NaCl}$ solution were refreshed every $2 \mathrm{~h}$, and their exchange defined the completion of a cycle of mineralization. The dentin slices were cleaned ultrasonically for 2 min after 
each cycle. The sample was taken out after two, four, and six cycles for assessment and then stored at $4{ }^{\circ} \mathrm{C}$ for further characterization.

\subsection{Characterization and Evaluation of New Crystal}

The morphology of new crystals and the chemical analysis with respect to the $\mathrm{Ca} / \mathrm{P}$ ratio of the remineralized dentin slices were evaluated using field-emission scanning electron microscopy (FE-SEM) and energy dispersive spectroscopy (EDS) (Hitachi S4800, Hitachi Ltd., Tokyo, Japan), respectively. Before the SEM, and EDS evaluation, all samples were dehydrated with gradual ethanol and dried in critical evaporator. The mechanical properties of remineralized dentin slices was evaluated by nanoindentation test. The elastic modulus and nanohardness of the dentin slices were evaluated by nanoindentation measurement (T1900 Nanomechanical Test Instrument, Hysitron Inc., Minneapolis, MN, USA). The duration for loading and unloading were both $15 \mathrm{~s}$, with holding time $10 \mathrm{~s}$ under the maximum applied force of $40 \mathrm{mN}$. For each of the samples, six sites were tested. The elastic modulus and nanohardness were calculated from the force-displacement curves by using Triboscan Quasi software. All data obtained were recorded and analyzed with statistical software (SPSS Statistic 25; IBM, Armonk, OH, USA). Differences were considered significant at $p<0.05$ ( $t$-test). Data were expressed as mean \pm standard deviation.

\section{Results}

\subsection{The Synthesis of GO}

In this study, the band at $3390 \mathrm{~cm}^{-1}$ was attributed to the $\mathrm{OH}$ stretching vibration due to the presence of surface hydroxyl groups (Figure 1). The band at $1715.31 \mathrm{~cm}^{-1}$ was the characteristic of the $\mathrm{C}=\mathrm{O}$ stretch of the carboxylic acid group in citric acid (Figure 1, line a). The C-O bonds were attributed by $1290.50 \mathrm{~cm}^{-1}$, presenting the oxide functional groups in the synthesized GO and confirming the successful carbonization of citric acid into GO (Figure 1, line b).

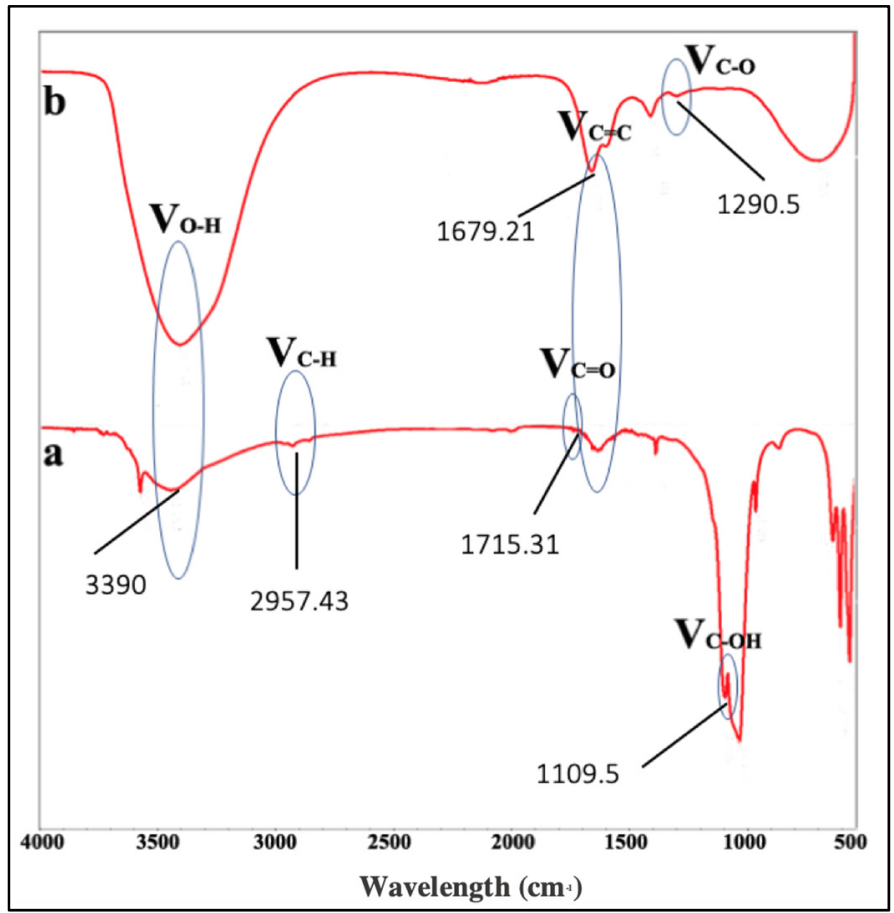

Figure 1. FTIR evaluation of citric acid and graphene oxide (GO). Line (a) shows the characteristic of the $\mathrm{C}=\mathrm{O}$ stretch of the carboxylic acid group in citric acid. Line (b) presents the oxide functional groups in the synthesized GO and confirms the successful carbonization of citric acid into graphite oxide. 
The UV-Vis region of energy for electromagnetic spectrum was observed in the range of 200-350 for UV and 350-700 for Vis. The absorption in the UV-Vis region is related to electric transitions in particles. Electronic transition occurs from bonding and/or nonbonding orbitals to the antibonding orbital when electromagnetic radiation absorbed. After carbonization, the color of citric acid changed into visible dark, and its UV-Vis absorption spectrum was also changed, due to the difference in molecular structure between citric acid and GO (Figure 2).

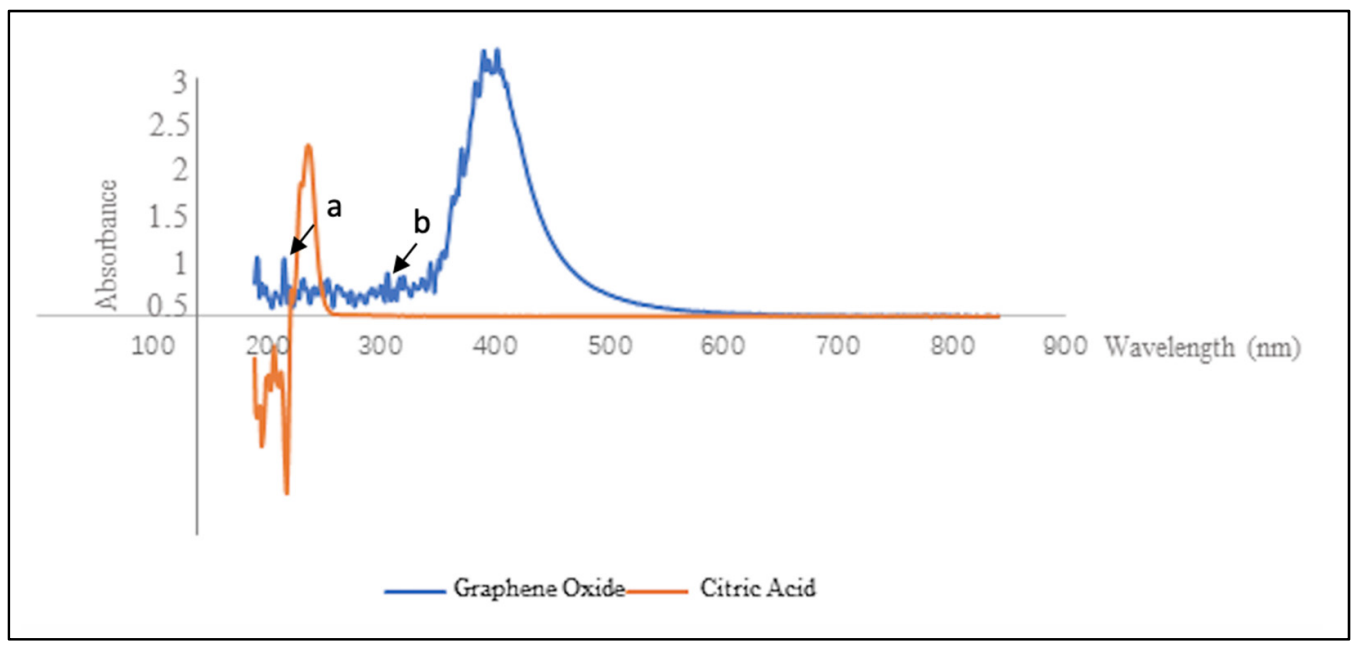

Figure 2. UV-visible adsorption spectrum of citric acid and GO. Arrow (a) represents $\pi-\pi^{*}$ transitions of aromatic $\mathrm{C}-\mathrm{C}$ bonds. Arrow $(\mathbf{b})$ represents $n-\pi^{*}$ transitions of $\mathrm{C}=\mathrm{O}$.

\subsection{Characterization of Remineralized Dentin Dlices}

Figure 3 illustrates the remineralized dentin slices after $8 \mathrm{~h}$ of remineralization. In the control group without the application of electrophoresis-aided system, only sporadic crystal was observed on the dentin surface. The vast majority of the dentinal tubules remained open (Figure 3a). In the experimental group with the aid of electrophoresis-aided system and addition of GO, acid-etched dentin slices were fully remineralized, and their surfaces were covered by the newly formed crystal layer (Figure 3b). The EDS spectrum showed the presence of higher amounts of carbon and oxygen (Figure $3 \mathrm{~d}$ ). This confirmed that the membrane contained GO to its surface, compared to pure HA (Figure 3c). Other elements are found as impurities on the membrane surface. Table 1 showed the concentration (wt.\%) of the major mineral component, suggesting higher concentration (wt.\%) of carbon and oxygen in the experimental group with addition of GO compared to pure control group.

Table 1. Average concentration (wt.\%) of control group (without the aid of electrophoresis) and experimental group (with the aid of electrophoresis) with addition of GO.

\begin{tabular}{ccc}
\hline $\begin{array}{c}\text { Concentration } \\
\text { (wt. } \%)\end{array}$ & $\begin{array}{c}\text { Control Group-Without the } \\
\text { Aid of Electrophoresis }\end{array}$ & $\begin{array}{c}\text { Experimental Group-With the Aid of } \\
\text { Electrophoresis and Addition of GO }\end{array}$ \\
\hline C & 6.198 & 8.842 \\
Ca & 42.524 & 37.644 \\
P & 19.604 & 18.726 \\
F & 4.792 & 5.223 \\
O & 26.883 & 29.565 \\
Ca/P ratio & 1.628 & 1.533 \\
\hline
\end{tabular}

After introduction of GO, crystals with different morphology were observed. The flake-like crystals were formed on the surface of acid-etched dentin in group A without the addition of GO (Figure 4), while rod-like crystals were obtained after the addition of GO (Figure 5). 


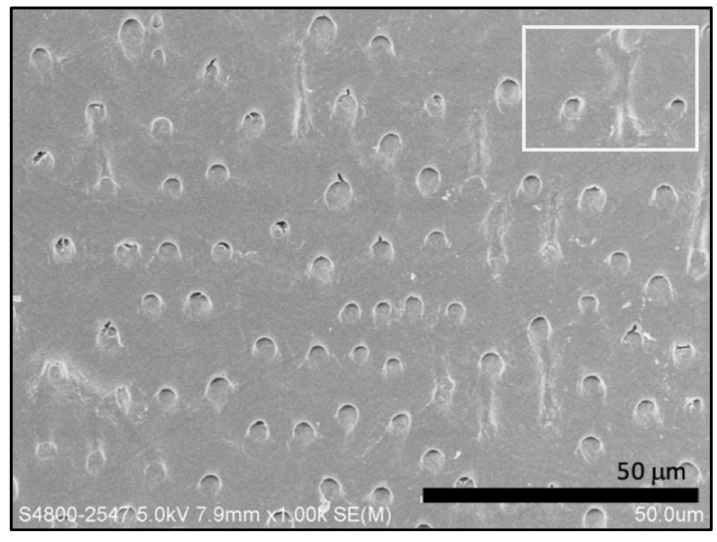

(a)

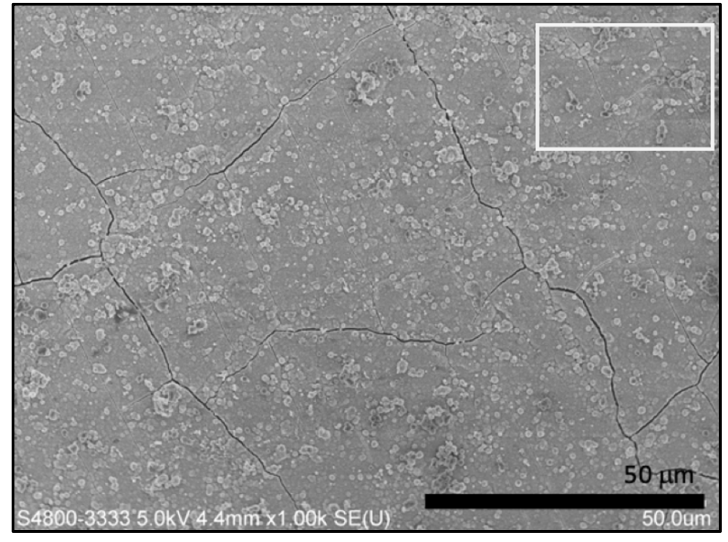

(b)

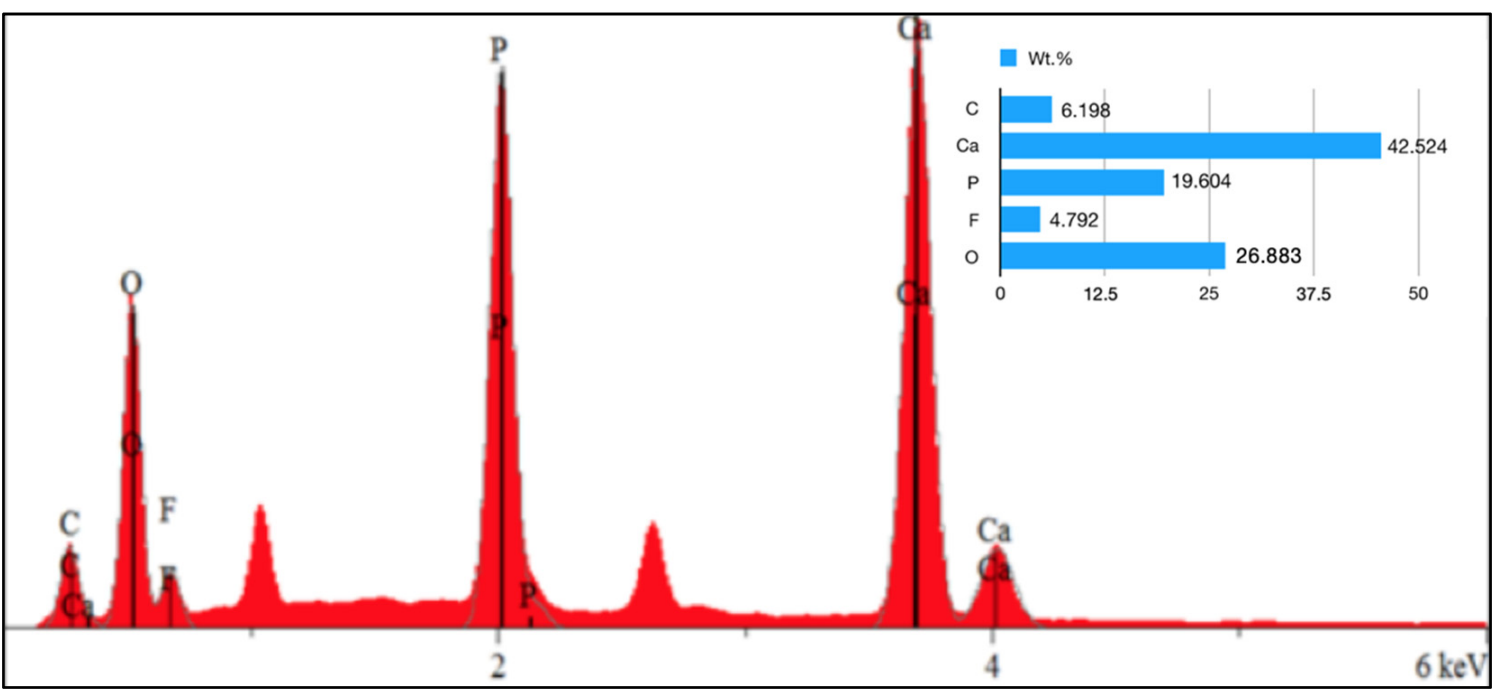

(c)

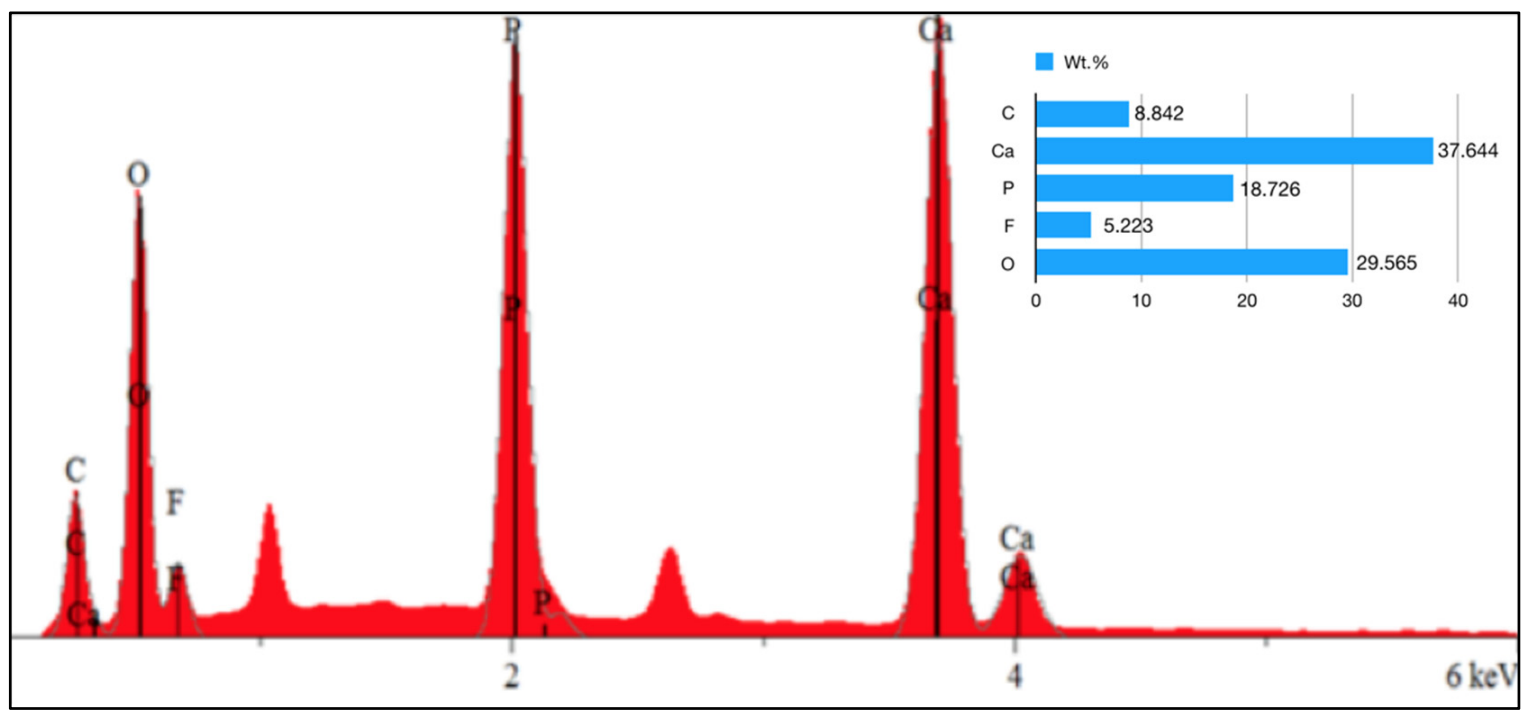

(d)

Figure 3. SEM micrograph of remineralized dentin slices; (a) dentin surface after remineralization without the aid of electrophoresis-aided system; (b) dentin surface after remineralization treated with electrophoresis-aided system and addition of GO; (c) energy dispersive spectroscopy (EDS) of remineralized area (rectangle) in (a); (d) EDS of remineralized area (rectangle) in (b). 


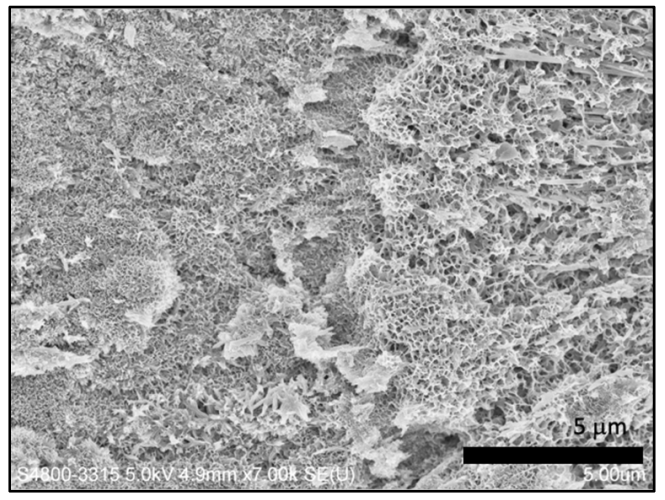

(a)

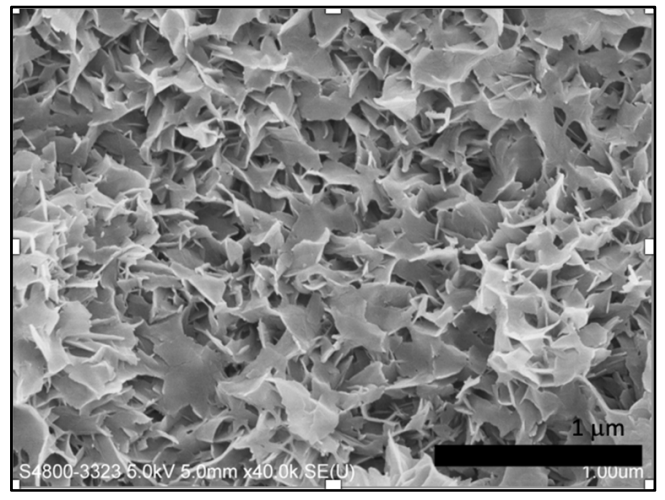

(b)

Figure 4. SEM micrograph of remineralized dentin surface in the experimental group without addition of GO: (a) with $7.00 \mathrm{k} \times$ magnification; (b) with $40.0 \mathrm{k} \times$ magnification.

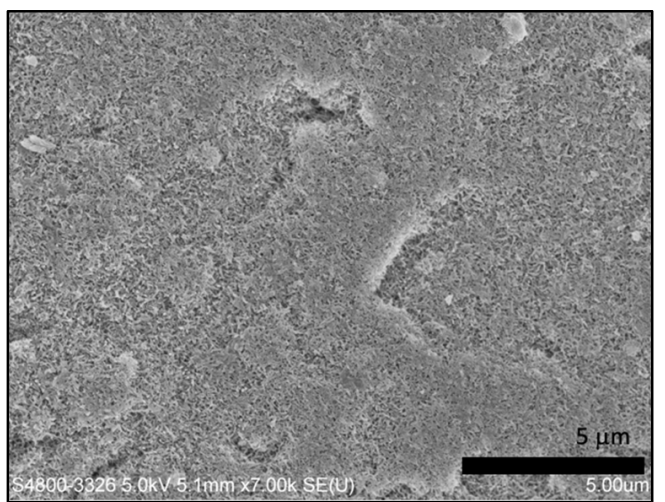

(a)

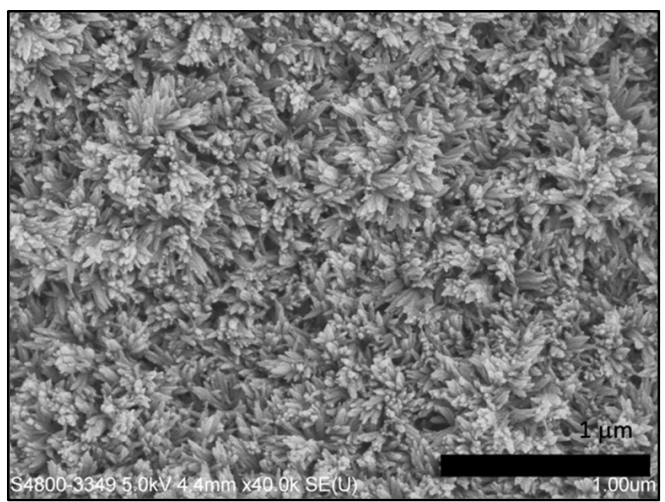

(b)

Figure 5. SEM micrograph of remineralized dentin surface in the experimental group with addition of GO: (a) with $7.00 \mathrm{k} \times$ magnification; (b) with $40.0 \mathrm{k} \times$ magnification.

\subsection{Mechanical Evaluation}

After $8 \mathrm{~h}$ of remineralization, the nanohardness of remineralized dentin slices in group A was significantly higher than that of acid-etched dentin slices $(0.347 \pm 0.128 ; p<0.0001)$ and reached to the level of nanohardness of native dentin slices $(1.068 \pm 0.042 ; p=0.885)$ (Figure 6a). The modulus of remineralized dentin slices in group A $(25.27 \pm 1.621)$ was significantly higher than that of acid-etched dentin slices $(7.275 \pm 0.213 ; p<0.0001)$ and that of native dentin slices $(20.60 \pm 1.146 ; p=0.04)$ (Figure $6 b)$.

The nanohardness of remineralized dentin slices in group B $(1.358 \pm 0.094)$ was significantly higher than those in group $A(p=0.0184)$, while the modulus of remineralized dentin slices in group B $(27.48 \pm 1.319)$ was similar to those in group A $(25.27 \pm 1.621$; $p=0.316)$. 


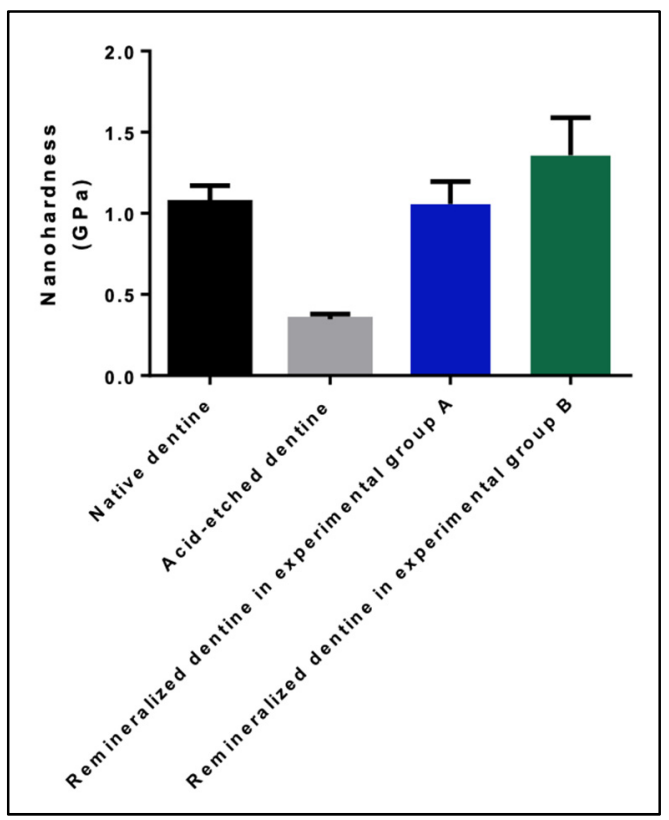

(a)

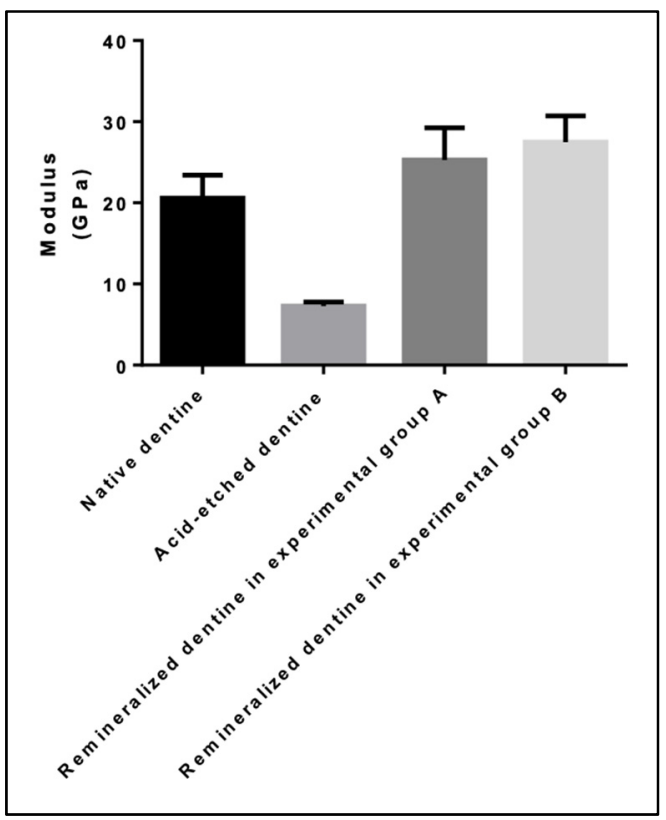

(b)

Figure 6. (a) Nanohardness and (b) modulus of native dentin slices, acid-etched dentin slices, remineralized dentin slices in experimental group $\mathrm{A}$ - without addition of $\mathrm{GO}$, and remineralized dentin slices in experimental group B-with addition of GO.

\section{Discussion}

Fourier transform infrared spectroscopy (FTIR) utilizes infrared radiation to detect functional groups found in materials. FTIR measures the absorption of infrared produced by the covalent bond in each molecule. Each bond and functional group absorb different frequencies, resulting in different transmittance patter for each molecule. The spectrum is recorded on $X$ and $Y$-axis as wavelength $\left(\mathrm{cm}^{-1}\right)$ and \% transmittance, respectively [31]. In this study, the result is in accordance with the study by Yang et al. and Hui et al. which showed the carbonization of citric acid into GO [32,33]. It was observed that no characteristic absorption bands of aromatic compound (stretching vibration of $\mathrm{C}-\mathrm{H}$ in aromatic rings around $3000-3100 \mathrm{~cm}^{-1}$, skeletal vibration of aromatic rings around $1450-1650 \mathrm{~cm}^{-1}$ ) was found in the FTIR spectrum. This suggested that there was no aromatic compound found in the GO synthesized (Figure 1).

The graphene synthesis process is a graphene fabrication process based on the desired size and quality. There are various approaches to synthesize GO and its derivatives. Methods such as mechanical cleavage (exfoliation), chemical synthesis, chemical exfoliation, epitaxial growth, and thermal chemical vapor deposition are widely known. Some other methods, namely electrochemical peeling, microwave synthesis, and carbon nanotube unzipping, have been reported. When massive production of graphene is required, methods such as top-down and bottom-up process of single layer graphene, bilayer graphene, and a few layers of graphene can be used. In top-down process, exfoliation or separation of highly ordered pyrolytic graphite or its derivatives was used to synthesize graphene sheets. On the other hand, graphene sheets were synthesized by building up nanoscale material via atomic or molecular arrangement of carbon in bottom-up process. [34]. In the present study, the GO was synthesized using bottom-up process by regulating carbonization degree of citric acid.

Different to that of citric acid, the unique atomic and electronic structure of variable $\mathrm{sp}^{2} / \mathrm{sp}^{3}$ fractions exists in GO [35]. GO can emit near-infrared, visible and ultraviolet photoluminescent, behaving in the form of the luminescence centers or chromophores, through the existence of geminate recombination of e-h pairs in the $\mathrm{sp}^{2}$ clusters $[36,37]$. 
GO solution can release blue light (460 nm) upon stimulation of $365 \mathrm{~nm}$ UV beam, which corresponds with the results in this study [37]. The UV-Vis adsorption of synthesized GO showed its maximum emission wavelength was $365 \mathrm{~nm}$; meanwhile, a shoulder around $320 \mathrm{~nm}$ was observed, which could be due to the $n-\pi^{*}$ transitions of $C=O$ [38]. This is consistent with the study conducted by Marcano et al. who examined improved synthesis of GO which showed that the UV- vis spectrum has a similar shoulder around $300 \mathrm{~nm}$ due to $n-\pi^{*}$ transitions of the carbonyl groups [39].

Another study by Khalili et al. observed the UV-Vis spectrum of GO, where the main spectrum of it has strong absorption point at $233 \mathrm{~nm}$, which is associated with the $\pi-\pi^{*}$ transition of the CC conjugated aromatic domain and weak absorption (shoulder) at $305 \mathrm{~nm}$. The UV-vis spectrum provides evidence of the presence of a number of oxygen functions, such as hydroxyl, carboxyl, epoxide, and carbonyl in grapheneoxidants [40].

Energy dispersive spectroscopy aims to determine the surface elemental composition of GO flakes. This method provides valuable information about the elemental composition of GO flakes. Since GO was acquired through carbonizing citric acid, thus it was observed that the carbon peak of GO-HA was stronger than that of pure HA.

Based on our previous study, the native dentin slices could be completely demineralized after treatment with $30 \%$ phosphate acid for $15 \mathrm{~s}$. All the dentin tubules and dentin collagen fibers could be exposed [2]. Due to the existence of extrinsic electric current, the mineralization speed was accelerated. The electric field is a method for manipulating bioparticles with strong control and ability with high efficiency, one of which is electrophoresis. Electrophoresis can deliver ions within teeth by forming electrical fields in the direction of low amperage electric currents. This is in accordance with the study by Zhang et al. which showed that electrophoresis introduced in their study in combination with CPP-ACP can accelerate the rate of remineralization [23]. A study by Wu et al. demonstrated an XRD pattern from crystals growing on the surface of dentin that are completely demineralized after remineralization for six cycles in a biomimetic mineralization system with the help of an electric field [22].

Compared to the flake-like crystals, rod-like crystals have a similar morphology to the crystals in native enamel. GO nanosheet is a monolayer of carbon atoms with condensed honeycomb structures, containing numerous reactive oxygen functional groups. Due to its excellent functionalization, GO has been widely applied as the precursor for biomimetic synthesis, especially for HA-based composite materials. Therefore, we could observe different crystal morphology being obtained after the addition of GO.

In the study by Nizami et al., GO-coated dentin slices were remineralized which resulted in almost completely sealed dentinal tubules compared to untreated dentin slices showing more open dentinal tubules (openings approximately $2 \mu \mathrm{m}$ in diameter). The results showed that the dentinal tubules were completely sealed with $\mathrm{GO}-\mathrm{Ag}-\mathrm{CaF}_{2}$, almost completely sealed with $\mathrm{GO}$ alone, $\mathrm{GO}-\mathrm{Ag}, \mathrm{GO}-\mathrm{CaF}_{2}, \mathrm{GO}-\mathrm{Ca}_{3}\left(\mathrm{PO}_{4}\right)_{2}$, and partially sealed with GO-Zn. In our study, only GO was used to enhance the remineralization, but the electrophoresis system was used to accelerate the process. Our finding was in line with the study by Nizami et al., in which the remineralization was observed for the group with the addition of GO. However, $8 \mathrm{~h}$ of mineralization time was needed in our study compared to $24 \mathrm{~h}$ of mineralization time in the study by Nizami et al. [41].

Graphene oxide has been known due to its excellent mechanical properties, which is attributed to the hexagonal lattice formed by stable $\mathrm{sp}^{2}$. The atoms in its honeycomb-like structure are combined with the $\mathrm{sp}^{2}$ clusters [42,43]. Graphite is a material consisting of three-dimensional carbon that has millions of layers of graphene. Graphite oxidation uses a strong oxidizing agent and its function is to expand the separation of the layers and also create a hydrophilic material. GO is a single-atom layered material composed of carbon, hydrogen and oxygen molecules through the oxidation of inexpensive and abundant graphite crystals [30,44,45]. Furthermore, GO has good biological properties and has been widely used in biomedical field, including drug delivery [46], cancer therapy [47,48], biosensing [49], tissue engineering [50], and bioimaging [51]. The use of GO can enhance 
cell proliferation and differentiation characteristics. A study by Chen et al. showed that the iPSC s cultured on GO surfaces spontaneously differentiated into ectodermal and mesodermal lineages uneventfully. The study concluded that GO is a promising material that can be used for iPSCs culture [52]. Evidence demonstrated that the mechanical performance and biocompatibility of HA had been improved significantly by reinforcement with GO [53].

In this study, it was observed that the result of experimental group B (with addition of GO) showed better result, suggesting that the addition of GO could effectively improve the nanohardness of remineralized dentin slice. Compared to enamel, dentin is more difficult to remineralize due to its different structure. Enamel has a high concentration of inorganic HA. The apatite crystals of demineralized enamel will continue to attract calcium and phosphorous ions which can facilitate remineralization. On the contrary, dentin consists of more organic substances including collagen fibrils. After demineralization, only a small amount of dentin can be reversed by surface remineralization, as well as growth and reproduction of crystalline cells. The mineralization of dentin occurs through noncollagenous protein regulation, deposition of calcium and phosphorus ions on dentinal collagen fibrils, and lastly formation of HA [54]. This difference is also related to the pattern of remineralization associated with the lower number of remaining crystals and the higher surface area of organic matrix (mainly type I collagen) found on the demineralized dentin surface. Furthermore, some studies showed that a portion of non-collagenous soluble protein released from dentin can inhibit remineralization [55].

The result of this study proved the ability of GO to promote HA crystal growth and the aid of electrophoresis system could accelerate the process. To date, there has been no clinical study conducted and it can be explored in future studies. Considering the shortened duration required to remineralize the tooth surface and the safety, electrophoresis has the potential to be applied clinically.

\section{Conclusions}

The introduction of electrophoresis system could significantly improve the generation of HA by GO. The occlusion of dentinal tubules with enamel-like tissue was observed on the dentin surfaces treated with electrophoresis with addition of GO. This study presented a promising way to mineralize dentin biomimetically.

Author Contributions: Conceptualization, I.P.K. and Y.Y.Z.; methodology, Y.Y.Z.; software, Y.Y.Z.; validation, I.P.K., Y.Y.Z., C.K.Y.Y. and H.M.W.; formal analysis, I.P.K. and Y.Y.Z.; investigation, I.P.K.; resources, H.M.W.; data curation, I.P.K.; writing-original draft preparation, I.P.K.; writing-review and editing, Y.Y.Z., C.K.Y.Y. and H.M.W.; visualization, Y.Y.Z. and H.M.W.; supervision, C.K.Y.Y. and H.M.W.; project administration, C.K.Y.Y. and H.M.W.; funding acquisition, H.M.W. All authors have read and agreed to the published version of the manuscript.

Funding: This research was funded by the NSFC/RGC Joint Research Scheme sponsored by the Research Grants Council of the Hong Kong Special Administrative Region, China and the National Natural Science Foundation of China (Project No. N_HKU706/20 and No. 82061160492).

Institutional Review Board Statement: The study was conducted according to the guidelines of the Declaration of Helsinki, and approved by the Institutional Review Board of University of Hong Kong and Hospital Authority Hong Kong West Cluster (UW 17-009).

Informed Consent Statement: Informed consent was obtained from all subjects involved in the study.

Data Availability Statement: The data presented in this study are available on request from the corresponding author.

Conflicts of Interest: The authors declare no conflict of interest. 


\section{References}

1. Chen, H.; Tang, Z.; Liu, J.; Sun, K.; Chang, S.-R.; Peters, M.C.; Mansfield, J.F.; Czajka-Jakubowska, A.; Clarkson, B.H. Acellular Synthesis of a Human Enamel-like Microstructure. Adv. Mater. 2006, 18, 1846-1851. [CrossRef]

2. Zhang, Y.Y.; Wong, H.M.; McGrath, C.P.J.; Li, Q.L. Repair of dentine-related lesions without a drill or injection. RSC Adv. 2019, 9 , 15099-15107. [CrossRef]

3. Crespi, R.; Capparè, P.; Gherlone, E. Comparison of Magnesium-Enriched Hydroxyapatite and Porcine Bone in Human Extraction Socket Healing: A Histologic and Histomorphometric Evaluation. Int. J. Oral Maxillofac. Implants 2011, 26, $1057-1062$.

4. Enax, J.; Fabritius, H.O.; Fabritius-Vilpoux, K.; Amaechi, B.T.; Meyer, F. Modes of action and clinical efficacy of particulate hydroxyapatite in preventive oral health care-State of the art. Open Dent. J. 2019, 13, 274-287. [CrossRef]

5. Hu, M.-L.; Zheng, G.; Zhang, Y.-D.; Yan, X.; Li, X.-C.; Lin, H. Effect of desensitizing toothpastes on dentine hypersensitivity: A systematic review and meta-analysis. J. Dent. 2018, 75, 12-21. [CrossRef] [PubMed]

6. Cao, Y.; Liu, W.; Ning, T.; Mei, M.L.; Mei, M.L.; Li, Q.-L.; Lo, E.C.M.; Chu, C.H. A novel oligopeptide simulating dentine matrix protein 1 for biomimetic mineralization of dentine. Clin. Oral Investig. 2014, 18, 873-881. [CrossRef]

7. Yamagishi, K.; Onuma, K.; Suzuki, T.; Okada, F.; Tagami, J.; Otsuki, M.; Senawangse, P. Materials chemistry: A synthetic enamel for rapid tooth repair. Nature 2005, 433, 819. [CrossRef] [PubMed]

8. Forsback, A.P.; Areva, S.; Salonen, J.I. Mineralization of dentin induced by treatment with bioactive glass S53P4 in vitro. Acta Odontol. Scand. 2004, 62, 14-20. [CrossRef]

9. Chen, H.; Clarkson, B.H.; Sun, K.; Mansfield, J.F. Self-assembly of synthetic hydroxyapatite nanorods into an enamel prism-like structure. J. Colloid. Interface Sci. 2005, 288, 97-103. [CrossRef]

10. Li, L.; Mao, C.; Wang, J.; Xu, X.; Pan, H.; Deng, Y.; Gu, X.; Tang, R. Bio-inspired enamel repair via Glu-directed assembly of apatite nanoparticles: An approach to biomaterials with optimal characteristics. Adv. Mater. 2011, 23, 4695-4701. [CrossRef] [PubMed]

11. Ruan, Q.; Zhang, Y.; Yang, X.; Nutt, S.; Moradian-Oldak, J. An amelogenin-chitosan matrix promotes assembly of an enamel-like layer with a dense interface. Acta Biomater. 2013, 9, 7289-7297. [CrossRef] [PubMed]

12. Fan, Y.; Wen, Z.T.; Liao, S.; Lallier, T.; Hagan, J.L.; Twomley, J.T.; Zhang, J.F.; Sun, Z.; Xu, X. Novel amelogenin-releasing hydrogel for remineralization of enamel artificial caries. J. Bioact. Compat. Polym. 2012, 27, 585-603. [CrossRef] [PubMed]

13. Busch, S. Regeneration of human tooth enamel. Angew. Chem. Int. Ed. Engl. 2004, 43, 1428-1431. [CrossRef] [PubMed]

14. Wu, D.; Yang, J.; Li, J.; Chen, L.; Tang, B.; Chen, X.; Wu, W.; Li, J. Hydroxyapatite-anchored dendrimer for in situ remineralization of human tooth enamel. Biomaterials 2013, 34, 5036-5047. [CrossRef] [PubMed]

15. Xie, R.; Feng, Z.; Li, S.; Xu, B. EDTA-Assisted Self-Assembly of Fluoride-Substituted Hydroxyapatite Coating on Enamel Substrate Cryst. Growth Des. 2011, 11, 5206-5214. [CrossRef]

16. Liu, S.; Yin, Y.; Chen, H. PEO-assisted precipitation of human enamel-like fluorapatite films for tooth whitening. Cryst. Eng. Comm. 2013, 15, 5853-5859. [CrossRef]

17. Zhou, Y.Z.; Cao, Y.; Liu, W.; Chu, C.H.; Li, Q.L. Polydopamine-induced tooth remineralization. ACS Appl. Mater. Interfaces 2012, 4 , 6901-6910. [CrossRef]

18. Tetè, G.; D'Orto, B.; Nagni, M.; Agostinacchio, M.; Polizzi, E.; Agliardi, E. Role of induced pluripotent stem cells (IPSCS) in bone tissue regeneration in dentistry: A narrative review. J. Biol. Regul. Homeost. Agents 2020, 34, 1-10.

19. Ramírez-Rodríguez, G.B.; Pereira, A.R.; Herrmann, M.; Hansmann, J.; Delgado-López, J.M.; Sprio, S.; Tampieri, A.; Sandri, M. Biomimetic Mineralization Promotes Viability and Differentiation of Human Mesenchymal Stem Cells in a Perfusion Bioreactor Int. J. Mol. Sci. 2021, 22, 1447. [CrossRef]

20. Wu, X.-T.; Cao, Y.; Mei, M.L.; Chen, J.-L.; Li, Q.-L.; Chu, C.H. An Electrophoresis-Aided Biomineralization System for Regenerating Dentin- and Enamel-Like Microstructures for the Self-Healing of Tooth Defects. Cryst. Growth Des. 2014, 14, 5537-5548. [CrossRef]

21. Watanabe, J.; Akashi, M. Novel Biomineralization for Hydrogels: Electrophoresis Approach Accelerates Hydroxyapatite Formation in Hydrogels. Biomacromolecules 2006, 7, 3008-3011. [CrossRef]

22. Wu, X.T.; Mei, M.L.; Li, Q.L.; Cao, C.Y.; Chen, J.L.; Xia, R.; Zhang, Z.H.; Chu, C.H. A Direct Electric Field-Aided Biomimetic Mineralization System for Inducing the Remineralization of Dentin Collagen Matrix. Materials 2015, 8, 7889-7899. [CrossRef]

23. Zhang, Y.Y.; Wong, H.M.; McGrath, C.P.J.; Li, Q.L. In vitro and in vivo evaluation of electrophoresis-aided casein phosphopeptideamorphous calcium phosphate remineralisation system on $\mathrm{pH}$-cycling and acid-etching demineralised enamel. Sci. Rep. 2018, 8, 8904. [CrossRef]

24. Nosrati, H.; Sarraf-Mamoory, R.; Le, D.Q.S.; Zolfaghari Emameh, R.; Canillas Perez, M.; Bünger, C.E. Improving the mechanical behavior of reduced graphene oxide/hydroxyapatite nanocomposites using gas injection into powders synthesis autoclave. Sci. Rep. 2020, 10, 8552. [CrossRef]

25. Wei, G.; Gong, C.; Hu, K.; Wang, Y.; Zhang, Y. Biomimetic Hydroxyapatite on Graphene Supports for Biomedical Applications: A Review. Nanomaterials 2019, 9, 1435. [CrossRef]

26. Li, X.; Wang, X.; Zhang, L.; Lee, S.; Dai, H. Chemically derived, ultrasmooth graphene nanoribbon semiconductors. Science 2008, 319, 1229-1232. [CrossRef]

27. Gao, F.; Xu, C.; Hu, H.; Wang, Q.; Gao, Y.; Chen, H.; Guo, Q.; Chen, D.; Eder, D. Biomimetic synthesis and characterization of hydroxyapatite/graphene oxide hybrid coating on Mg alloy with enhanced corrosion resistance. Mater. Lett. 2015, 138, 25-28. [CrossRef] 
28. Mei, M.L.; Ito, L.; Cao, Y.; Li, Q.L.; Lo, E.C.; Chu, C.H. Inhibitory effect of silver diamine fluoride on dentine demineralisation and collagen degradation. J. Dent. 2013,41, 809-817. [CrossRef]

29. Dong, Y.; Shao, J.; Chen, C.; Li, H.; Wang, R.; Chi, Y.; Lin, X.; Chen, G. Blue luminescent graphene quantum dots and graphene oxide prepared by tuning the carbonization degree of citric acid. Carbon 2012, 50, 4738-4743. [CrossRef]

30. Wong, H.M.; Zhang, Y.Y.; Li, Q.L. An enamel-inspired bioactive material with multiscale structure and antibacterial adhesion property. Bioact. Mater. 2022, 7, 491-503. [CrossRef]

31. Khan, S.; Khan, S.; Khan, L.; Farooq, A.; Akhtar, K.; Asiri, A.M. Fourier Transform Infrared Spectroscopy: Fundamentals and Application in Functional Groups and Nanomaterials Characterization. In Handbook of Materials Characterization; Springer: Berlin/Heidelberg, Germany, 2018; pp. 317-344.

32. Yang, K.; Zhang, S.; Zhang, G.; Sun, X.; Lee, S.-T.; Liu, Z. Graphene in Mice: Ultrahigh In Vivo Tumor Uptake and Efficient Photothermal Therapy. Nano Lett. 2010, 10, 3318-3323. [CrossRef]

33. Liu, H.; Xi, P.; Xie, G.; Shi, Y.; Hou, F.; Huang, L.; Chen, F.; Zeng, Z.; Shao, C.; Wang, J. Simultaneous Reduction and Surface Functionalization of Graphene Oxide for Hydroxyapatite Mineralization. J. Phys. Chem. C 2012, 116, 3334-3341. [CrossRef]

34. Adetayo, A.; Runsewe, D. Synthesis and Fabrication of Graphene and Graphene Oxide: A Review. Open J. Compos. Mater. 2019, 9 , 207-229. [CrossRef]

35. Eda, G.; Lin, Y.Y.; Mattevi, C.; Yamaguchi, H.; Chen, H.A.; Chen, I.S.; Chen, C.W.; Chhowalla, M. Blue photoluminescence from chemically derived graphene oxide. Adv. Mater. 2010, 22, 505-509. [CrossRef]

36. Lee, W.C.; Lim, C.H.Y.X.; Shi, H.; Tang, L.A.L.; Wang, Y.; Lim, C.T.; Loh, K.P. Origin of Enhanced Stem Cell Growth and Differentiation on Graphene and Graphene Oxide. ACS Nano 2011, 5, 7334-7341. [CrossRef]

37. Luo, Z.; Lu, Y.; Somers, L.A.; Johnson, A.T.C. High Yield Preparation of Macroscopic Graphene Oxide Membranes. J. Am. Chem. Soc. 2009, 131, 898-899. [CrossRef]

38. Zeng, Y.; Pei, X.; Yang, S.; Qin, H.; Cai, H.; Hu, S.; Sui, L.; Wan, Q.; Wang, J. Graphene oxide/hydroxyapatite composite coatings fabricated by electrochemical deposition. Surf. Coat. Technol. 2016, 286, 72-79. [CrossRef]

39. Marcano, D.C.; Kosynkin, D.V.; Berlin, J.M.; Sinitskii, A.; Sun, Z.; Slesarev, A.; Alemany, L.B.; Lu, W.; Tour, J.M. Improved Synthesis of Graphene Oxide. ACS Nano 2010, 4, 4806-4814. [CrossRef]

40. Khalili, D. Graphene oxide: A promising carbocatalyst for the regioselective thiocyanation of aromatic amines, phenols, anisols and enolizable ketones by hydrogen peroxide/KSCN in water. New J. Chem. 2016, 40, 2547-2553. [CrossRef]

41. Nizami, M.Z.I.; Nishina, Y.; Yamamoto, T.; Shinoda-Ito, Y.; Takashiba, S. Functionalized Graphene Oxide Shields Tooth Dentin from Decalcification. J. Dent. Res. 2020, 99, 182-188. [CrossRef]

42. Chen, J.; Li, H.; Zhang, L.; Du, C.; Fang, T.; Hu, J. Direct Reduction of Graphene Oxide/Nanofibrillated Cellulose Composite Film and its Electrical Conductivity Research. Sci. Rep. 2020, 10, 3124. [CrossRef]

43. Ambrosio, G.; Drera, G.; Di Santo, G.; Petaccia, L.; Daukiya, L.; Brown, A.; Hirsch, B.; De Feyter, S.; Sangaletti, L.; Pagliara, S Interface Chemistry of Graphene/Cu Grafted By 3,4,5-Tri-Methoxyphenyl. Sci. Rep. 2020, 10, 4114. [CrossRef]

44. Nazri, S.R.B.; Liu, W.-W.; Khe, C.-S.; Hidayah, N.M.S.; Teoh, Y.-P.; Voon, C.H.; Lee, H.C.; Adelyn, P.Y.P. Synthesis, characterization and study of graphene oxide. AIP Conf. Proc. 2018, 2045, 020033. [CrossRef]

45. Liu, S.; Zeng, T.H.; Hofmann, M.; Burcombe, E.; Wei, J.; Jiang, R.; Kong, J.; Chen, Y. Antibacterial Activity of Graphite, Graphite Oxide, Graphene Oxide, and Reduced Graphene Oxide: Membrane and Oxidative Stress. ACS Nano 2011, 5, 6971-6980. [CrossRef]

46. Pei, X.; Zhu, Z.; Gan, Z.; Chen, J.; Zhang, X.; Cheng, X.; Wan, Q.; Wang, J. PEGylated nano-graphene oxide as a nanocarrier for delivering mixed anticancer drugs to improve anticancer activity. Sci. Rep. 2020, 10, 2717. [CrossRef]

47. Rosso, M.; Blasi, G.; Gherlone, E.; Rosso, R. Effect of granulocyte-macrophage colony-stimulating factor on prevention of mucositis in head and neck cancer patients treated with chemo-radiotherapy. J. Chemother. 1997, 9, 382-385. [CrossRef]

48. Muñoz, R.; Singh, D.P.; Kumar, R.; Matsuda, A. Chapter 22-Graphene Oxide for Drug Delivery and Cancer Therapy. In Nanostructured Polymer Composites for Biomedical Applications; Swain, S.K., Jawaid, M., Eds.; Elsevier: Amsterdam, The Netherlands, 2019 ; pp. 447-488.

49. Garg, K.; Papponen, P.; Johansson, A.; Puttaraksa, N.; Gilbert, L. Preparation of graphene nanocomposites from aqueous silver nitrate using graphene oxide's peroxidase-like and carbocatalytic properties. Sci. Rep. 2020, 10, 5126. [CrossRef]

50. Adamowicz, J.; Pasternak, I.; Kloskowski, T.; Gniadek, M.; Van Breda, S.V.; Buhl, M.; Balcerczyk, D.; Gagat, M.; Grzanka, D.; Strupinski, W.; et al. Development of a conductive biocomposite combining graphene and amniotic membrane for replacement of the neuronal network of tissue-engineered urinary bladder. Sci. Rep. 2020, 10, 5824. [CrossRef]

51. Lin, J.; Huang, Y.; Huang, P. Chapter 9-Graphene-Based Nanomaterials in Bioimaging. In Biomedical Applications of Functionalized Nanomaterials; Sarmento, B., das Neves, J., Eds.; Elsevier: Amsterdam, The Netherlands, 2018; pp. 247-287.

52. Chen, G.Y.; Pang, D.W.; Hwang, S.M.; Tuan, H.Y.; Hu, Y.C. A graphene-based platform for induced pluripotent stem cells culture and differentiation. Biomaterials 2012, 33, 418-427. [CrossRef]

53. Baradaran, S.; Moghaddam, E.; Basirun, W.J.; Mehrali, M.; Sookhakian, M.; Hamdi, M.; Moghaddam, M.R.N.; Alias, Y. Mechanical properties and biomedical applications of a nanotube hydroxyapatite-reduced graphene oxide composite. Carbon 2014, 69, 32-45. [CrossRef]

54. Zhou, Z.; Ge, X.; Bian, M.; Xu, T.; Li, N.; Lu, J.; Yu, J. Remineralization of dentin slices using casein phosphopeptide-amorphous calcium phosphate combined with sodium tripolyphosphate. Biomed. Eng. Online 2020, 19, 18. [CrossRef] [PubMed]

55. Zhang, X.; Neoh, K.G.; Lin, C.C.; Kishen, A. Remineralization of partially demineralized dentine substrate based on a biomimetic strategy. J. Mater. Sci. Mater. Med. 2012, 23, 733-742. [CrossRef] [PubMed] 